\title{
Insulin-like growth factor binding protein 5 (IGFBP5) functions as a tumor suppressor in human melanoma cells
}

\author{
Junyun Wang ${ }^{1,2, *}$, Nan Ding ${ }^{1,2, *}$, Yongjun Li ${ }^{1, *}$, Hua Cheng ${ }^{3, *}$, Dong Wang4, Qiong \\ Yang $^{1,2}$, Youhui Deng ${ }^{1,2}$, Yaran Yang ${ }^{1}$, Yanming Li ${ }^{1}$, Xiuyan Ruan ${ }^{1}$, Fang Xie ${ }^{4}$, Hua \\ Zhao $^{4}$ and Xiangdong Fang ${ }^{1}$ \\ ${ }^{1}$ CAS Key Laboratory of Genome Sciences and Information, Beijing Institute of Genomics, Chinese Academy of Sciences, \\ Beijing, China \\ ${ }^{2}$ University of Chinese Academy of Sciences, Beijing, China \\ ${ }^{3}$ Institute of Biology, Hebei Academy of Sciences, Shijiazhuang, China \\ ${ }^{4}$ Department of Dermatology, General Hospital of People's Liberation Army, Beijing, China \\ * These authors have contributed equally to this work \\ Correspondence to: Xiangdong Fang, email: fangxd@big.ac.cn \\ Hua Zhao, email: Iuckhua301@163.com \\ Keywords: IGFBP5; malignant melanoma; tumor suppressor; EMT; ERK-MAPK \\ Received: March 19, $2015 \quad$ Accepted: April 22, $2015 \quad$ Published: May 12, 2015
}

This is an open-access article distributed under the terms of the Creative Commons Attribution License, which permits unrestricted use, distribution, and reproduction in any medium, provided the original author and source are credited.

\section{ABSTRACT}

The insulin-like growth factor binding protein 5 (IGFBP5), which is often dysregulated in human cancers, plays a crucial role in carcinogenesis and cancer development. However, the function and underlying mechanism of IGFBP5 in tumor growth and metastasis has been elusive, particularly in malignant human melanoma. Here, we reported that IGFBP5 acts as an important tumor suppressor in melanoma tumorigenicity and metastasis by a series of experiments including transwell assay, xenograft model, in vivo tumor metastasis experiment, and RNA-Seq. Overexpression of IGFBP5 in A375, a typical human melanoma cell line, inhibited cell malignant behaviors significantly, including in vitro proliferation, anchorage-independent growth, migration and invasion, as well as in vivo tumor growth and pulmonary metastasis. In addition, overexpression of IGFBP5 suppressed epithelial-mesenchymal transition (EMT), and decreased the expression of E-cadherin and the key stem cell markers NANOG, SOX2, OCT4, KLF4, and CD133. Furthermore, IGFBP5 exerts its inhibitory activities by reducing the phosphorylation of IGF1R, ERK1/2, and p38MAPK kinases and abating the expression of HIF1a and its target genes, VEGF and MMP9. All these findings were confirmed by IGFBP5 knockdown in human melanoma cell line A2058. Taken together, these results shed light on the mechanism of IGFBP5 as a potential tumor-suppressor in melanoma progression, indicating that IGFBP5 might be a novel therapeutic target for human melanoma.

\section{INTRODUCTION}

The insulin-like growth factor binding proteins (IGFBPs) comprise a family of six proteins that function as critical regulators of the bioavailability and mitogenic activities of insulin-like growth factors (IGFs). IGFBP5, the most conserved member of the IGFBPs family, is frequently dysregulated in human cancers and metastatic tissues $[1,2]$. IGFBP5 has several functional roles in carcinogenesis and cancer development, which can determine cell survival and regulate cell growth, migration, and invasion in the development of cancer. Many preclinical studies indicate that IGFBP5 can suppress tumor growth and metastasis in various tissues and contexts, but IGFBP5 can also function as an oncogene, promoting metastasis in a context-dependent manner [2-4]. IGFBP5 modulates cell functions by both IGF-dependent mechanisms, which affect IGF 1 receptor 
(IGF1R) signaling, and IGF-independent mechanisms that do not alter IGF1R signaling [3]. Furthermore, the different domains of IGFBP5 exert distinct effects on the tumorigenicity and metastasis of different human cancers $[5,6]$.

Despite the increasing number of studies supporting the role of IGFBP5 in tumorigenesis and metastasis in several types of cancers, its function in the progression of cancer is controversial and few studies have provided mechanistic insights for IGFBP5 in human malignant melanoma (MM). MM is one of the most lethal forms of skin cancer, and its incidence has been rising for, at least, the past 30 years $[7,8]$. In patients with MM, tumor metastasis is highly aggressive and is the leading cause of mortality. The molecular mechanisms underlying the development and progression of melanoma are still not well understood, demonstrating the need for novel diagnostic markers and therapeutic targets to combat MM. Other IGFBPs family members, such as IGFBP3, have been associated with melanoma progression [9-12]. Thus, it is imperative to determine the roles of IGFBP5 in melanoma.

Our previous study revealed that IGFBP5 exhibited a distinctly different expression pattern in melanoma cells with RNA-sequencing (RNA-Seq) [13]. Hence, in order to define the role of IGFBP5 in MM growth and metastasis, we investigated the effects of IGFBP5 in A375 and A2058 human melanoma cells and its potential as a potent tumor growth inhibitor and anti-metastatic agent both in vitro and in vivo, using stable overexpression and knockdown cells. Our findings provide new insights into the mechanism by which IGFBP5 suppresses the proliferation and invasion of melanoma cells.

\section{RESULTS}

\section{IGFBP5 expression is associated with melanoma}

A critical question that has been raised is whether the expression of IGFBP5 clinically correlates with the progression of human melanoma. To address this issue, we studied IGFBP5 expression in HEMn-LP normal melanocytes and three human melanoma cell lines (A375, A2058, and UACC903) using quantitative real-time PCR (qRT-PCR). We found that IGFBP5 was highly expressed in A2058 and UACC903 cells, but low expression in HEMn-LP and A375 cells relatively (Figure 1A).

In clinical samples, the expression of IGFBP5 in melanoma samples $(n=10)$ is higher than in normal pigmented nevus samples $(n=5)$ significantly by qRTPCR analysis $(*, p<0.05$, Figure 1B). Furthermore, we analyzed the expression of IGFBP5 by hematoxylineosin (H\&E) and immunohistochemical (IHC) staining in human pigmented nevus samples $(n=7)$, primary human melanoma samples $(n=7)$, and human metastatic melanoma samples $(n=8)$. IHC staining was graded in four categories: IHC $3+, 2+, 1+$ and 0 -. Our results revealed that the mean $\mathrm{IHC}$ score for all the melanoma samples was 1.8 compared to 0.4 for the pigment nevus tissues $(*, p<0.05)$. Figure $1 \mathrm{C}$ illustrates the strong staining for IGFBP5 from a primary melanoma sample compared to the weak staining from a metastatic tissue and a normal pigmented nevus sample.

\section{IGFBP5 inhibits melanoma cell proliferation and suppresses tumor growth in vivo}

To investigate the role of IGFBP5 in melanoma progression, we stably transfected the human melanoma cell line A375 with IGFBP5, which enabling high expression of IGFBP5, as shown with western blot (WB) and qRT-PCR (Figure 2, panels A1 and A2). Using this stable IGFBP5 overexpression (OE) cell line, we assessed the effects of IGFBP5 on cell proliferation and tumor growth using CCK-8 assay and colony formation assay. Our results demonstrate that elevated expression of IGFBP5 inhibited cell proliferation significantly in vitro. (Figure 2, panel B and C).

To confirm the inhibitory effects of IGFBP5 on tumor growth in vivo further, A375 vector control and $\mathrm{OE}$ cells were implanted subcutaneously into the abdomens of SCID/Beige mice. As a result, all mice developed tumors at their injection sites. Remarkably, IGFBP5 inhibited tumor growth in IGFBP5 OE mice significantly (mean tumor weight: $\left.0.018 \pm 0.008 \mathrm{~g},{ }^{*}, p<0.05\right)$, whereas the tumors of the control group grew far larger (mean tumor weight: $1.73 \pm 0.46 \mathrm{~g}$ ) (Figure 2D).

We further investigated the function of IGFBP5 using stable IGFBP5 knockdown (KD) A2058 cells. The expression of IGFBP5 decreased by $90 \%$ compared to the control by WB and qRT-PCR analyses. Consistent with IGFBP5 overexpression results, down-regulation of IGFBP5 promoted cell proliferation and tumor growth significantly (Figure S1). Together, these data substantially demonstrate that IGFBP5 functions as a tumor suppressor for melanoma tumor growth.

\section{IGFBP5 represses tumor cell migration, invasion, and suppresses pulmonary metastasis in vivo}

To explore the effects of IGFBP5 on MM progression, we conducted a series of tumor migration and invasion assays in vitro with stably transfected A 375 $\mathrm{OE}$ cells and in vivo in xenograft mice. Up-regulation of IGFBP5 markedly inhibited cell migration through a permeable filter ( $92 \%$ suppression) and invasion through a Matrigel matrix (96\% suppression) compared to controls ( $*, p<0.05$, Figure 3, panels A and B). Conversely, down-regulation of IGFBP5 promoted cell migration and 
invasion significantly $(*, p<0.05$, Figure S2, panels A and B). Subsequently, we performed pulmonary metastasis assays in SCID/Beige mice. The pulmonary metastatic clusters, which presented in the mice with OE cells $(2.2 \pm$ 3.3 clusters per lung, $\left.{ }^{*}, p<0.05\right)$, were significantly fewer than those in the control group $(52.3 \pm 12.3$ clusters per lung), as shown by H\&E staining. Notably, overexpression of IGFBP5 rarely formed secondary metastases in the lungs of mice, whereas control mice were found to have extensive and severe metastatic deposits in both lungs (Figure 3, panel C and D).

We next examined the effects of IGFBP5 KD on A2058 cell migration and metastasis and observed that down-regulation of IGFBP5 promoted the formation of micrometastases in the IGFBP5 KD mice. Pulmonary metastases were easily detected when endogenous expression of IGFBP5 was knocked down in A2058 cells $\left(95.8 \pm 38.8\right.$ clusters per lung, ${ }^{*}, p<0.05$.), whereas fewer and smaller metastases were observed in scramble control mice $(27.3 \pm 20.0$ clusters per lung) (Figure S2, panels $\mathrm{C} 1$ and $\mathrm{C} 2$ ). Representative H\&E staining of lung tumor sections and adjacent tissues from IGFBP5 knockdown mice and control mice was shown (Figure S2, panels D1 and D2). Collectively, these observations indicate that IGFBP5 negatively regulated the metastatic properties of melanoma cancer cells both in vitro and in vivo.

\section{IGFBP5 suppresses EMT and stem cell features of tumor cells}

Given that IGFBP5 inhibited cancer metastasis and characteristic morphological changes were observed in A375 and A2058 (Figure 4A and Figure S3A), we investigated whether IGFBP5 plays a role in regulating EMT, a critical event in tumor invasion and progression. Accordingly, we tested EMT-associated markers with WB and immunofluorescence and found that A2058 cells
A

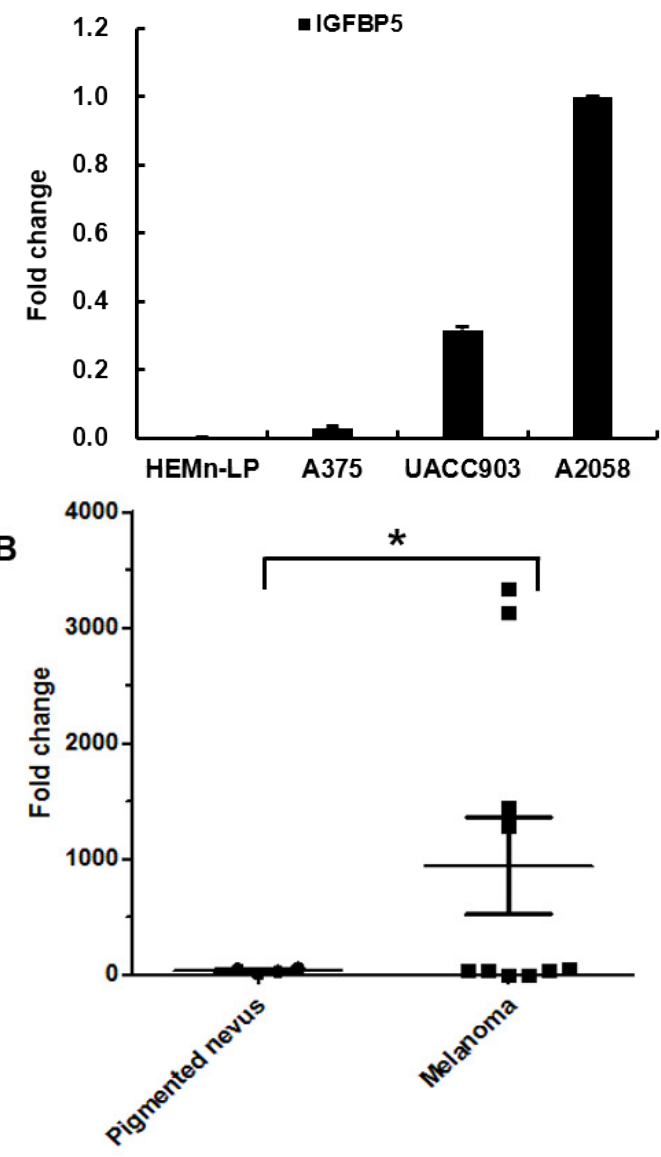

C
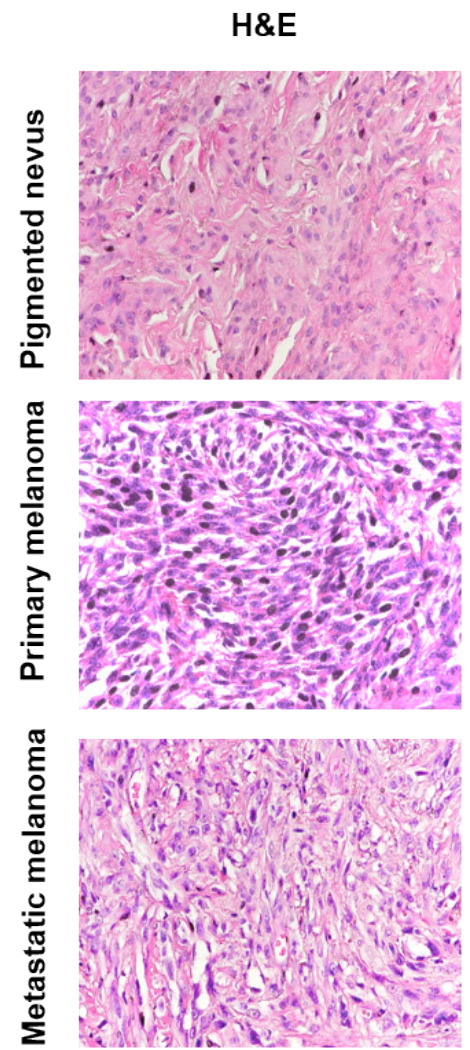

IGFBP5
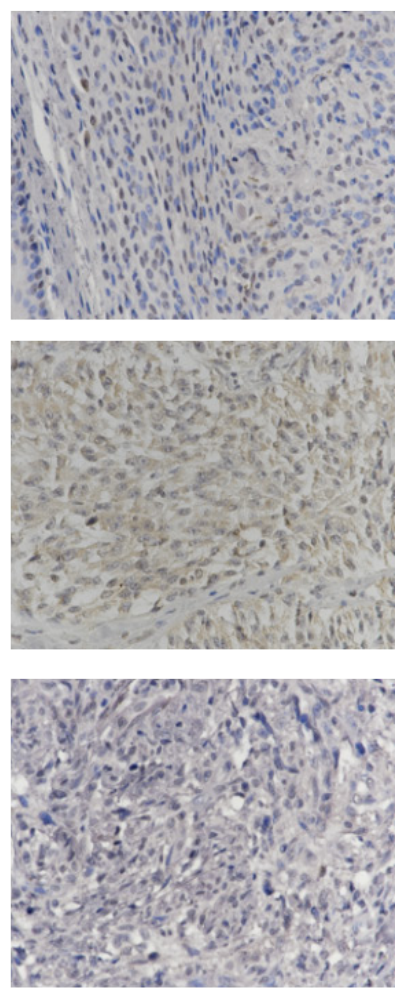

Figure 1: IGFBP5 expression in cell lines and clinical melanoma samples. A. The relative endogenous expression of $I G F B P 5$ analyzed for in HEMn-LP and the 3 MM cell lines, A375, UACC903, and A2058 by qRT-PCR. GAPDH was used as the internal control. B. qRT-PCR analysis of the expression of IGFBP5 in normal pigmented nevus samples $(n=5)$ and melanoma samples $(n=10)$ collected from General Hospital of PLA. Data were shown for the mean \pm standard deviation (SD) from three independent experiments. *, $P<0.05$. C. Representative H\&E and immunohistochemical (IHC) stains of a normal pigmented nevus, a primary melanoma tissue, and a lymph node metastatic tissue. The mean IHC scores of the melanoma tissues and the pigment nevus tissues were 1.8 and $0.4 .^{*}, P<0.05$. IGFBP5 staining was intense in the primary tumor tissues and that was weak in the normal pigmented nevus and metastatic tumor tissues. The magnifications of the images were $\times 400$. 
transfected with IGFBP5-targeting shRNA exhibited prominent mesenchymal-like phenotypes, including a fibroblast-like morphology. We also observed an increase in the expression of the mesenchymal marker vimentin (VIM) and a decrease of the epithelial marker E-cadherin (ECAD) (Figure S3, panels A - C). However, overexpression of IGFBP5 in A375 cells led to a cobblestone morphology in monolayer cultures with tight cell-cell contacts, characteristic of normal epithelial cells (Figure 4A), indicating that IGFBP5 most likely reversed tumor cell EMT. This morphological change accompanied by an increase in the expression of ECAD and a decrease in VIM. These results were also confirmed by $\mathrm{WB}$ and immunofluorescence assays (Figure 4B and 4C).

To determine whether IGFBP5-inhibited EMTs affect the generation of cancer stem cell (CSC)-like cells, we performed qRT-PCR to analyze the master stem cell transcription factors (TFs) in OE cells. We found that overexpression of IGFBP5 decreased expression of the stem cell TFs: NANOG, SOX2, KLF4, and OCT4, at the transcriptional level (Figure 4D), and the expression of these stem cell TFs were increased in IGFBP5 KD A2058 cells (Figure S3D). Furthermore, we tested the expression of the stem cell marker, CD133, in melanoma clones.
IGFBP5-silenced A2058 cells acquired a higher CD133 expression phenotype than control cells (Figure S3, panels E and F). By contrast, A375 OE cells showed a reduced CD133 expression phenotype compared to GFP control cells (Figure 4, panels E and F).

We sequenced the RNA transcriptome of A375 IGFBP5 OE cells using RNA-Seq methodology and found that the changes in the expression of the EMT markers were consistent with the variations detected with both the WB and immunofluorescence assays. The melanoma CSC markers SOX2, KLF4, and CD271 exhibited reduced expression profiles in the A375 IGFBP5 OE cells compared to empty vector control cells (Figure 5A). Intriguingly, genes from the "Regulation of the EMT Pathway" and three other pathways related to stem cell pluripotency ("Human Embryonic Stem Cell Pluripotency", "Role of NANOG in Mammalian Embryonic Stem Cell Pluripotency", and "Role of OCT4 in Mammalian Embryonic Stem Cell Pluripotency"), were categorized among those most altered with the Ingenuity Pathway Analysis (IPA) software (Figure 5B). Taken together, these results suggest that IGFBP5 inhibited both the EMT procession and stem cell properties of melanoma cells.

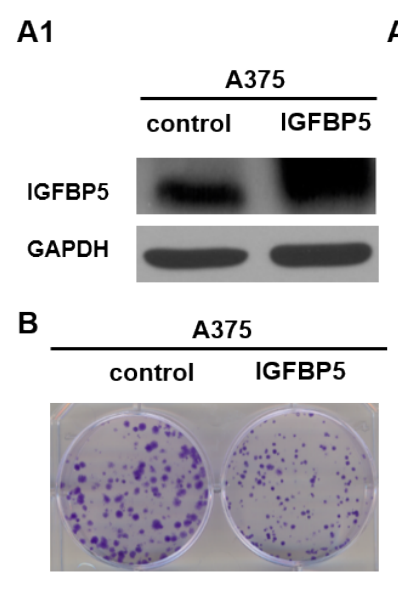

C
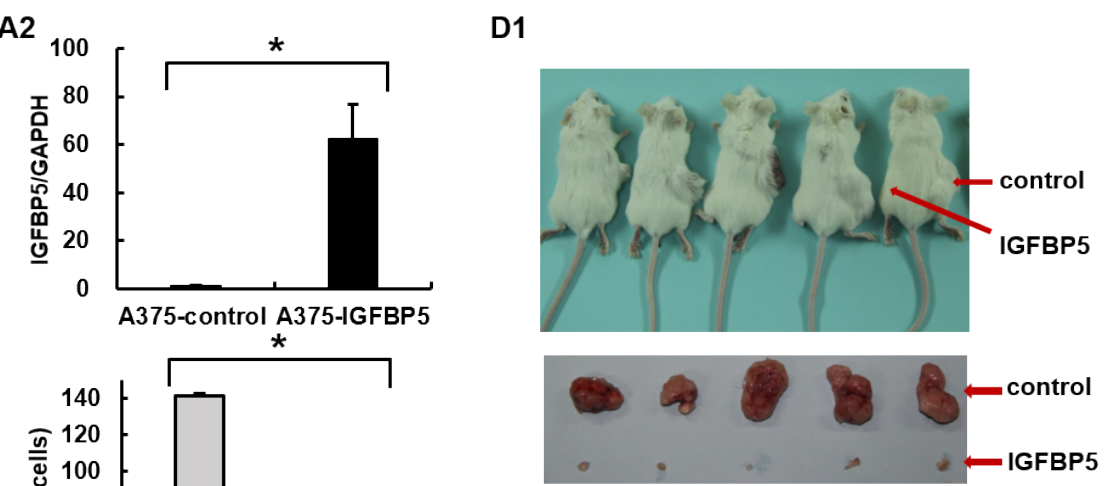

D2

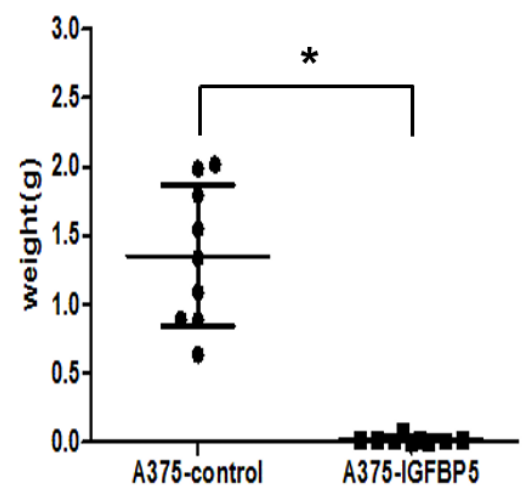

Figure 2: IGFBP5 inhibits melanoma cell proliferation both in vitro and in vivo. A. A375 melanoma cells were transfected with pcDNA3.1-Neo-EGFP-IGFBP5 and empty pcDNA3.1-Neo-EGFP vectors. Western blots (left) and qRT-PCR (right) analyses were used to detect IGFBP5 expression in transfected cells. Colony formation assay B. , CCK-8 assay C. , and xenograft assay D. were used to explore the effects of stable IGFBP5 overexpression on melanoma cell proliferation. Data were shown for the mean \pm SD from three independent experiments. $P$ values based on two-side Student $t$-test comparing control and IGFBP5 OE. ${ }^{*}, P<0.05$. 
IGFBP5 affects melanoma growth and metastasis through inhibition of the extracellular signalregulated kinase (ERK) and p38-MAPK signaling pathways

It is well established that human MM is driven by the activation of ERK-MAPK signaling, and most frequently through mutations in the BRAF or NRAS oncogenes. To test whether IGFBP5 suppressed melanoma growth and metastasis through inhibition of this signaling pathway, we examined the phosphorylation of ERK and p38-MAPK and found that their phosphorylation levels decreased in A375 IGFBP5 OE cells and increased in A2058 IGFBP5 KD cells (Figures 6, panels A and B, and Figures S4, panels A and B). Furthermore, we found IGFBP5 down-regulated the expression of the hypoxiainducible factor $1 \alpha(\mathrm{HIF} 1 \alpha)$ in A375 IGFBP5 OE cells, and the genes targeted by HIF1 $\alpha$, VEGFA and MMP9, were also dramatically reduced. Similarly, we also observed that HIF $1 \alpha$ increased in IGFBP5 KD cells, and
VEGFA and MMP9 were correspondingly elevated 18.3fold and 7.5-fold, respectively. These results imply that IGFBP5 may mediate HIF1 $\alpha$ expression to inhibit tumor growth and metastasis (Figures 6, panels $\mathrm{C}$ and $\mathrm{D}$, and Figures S4, panels C and D).

To determine the molecular mechanisms of IGFBP5 functions in MM, we performed RNA-Seq analysis of A375 IGFBP5 OE cells using the Ion Proton ${ }^{\mathrm{TM}}$ system. We analyzed the differences in gene expression and gene function with IPA software, and the results confirmed our experimental findings (Figure 5, panels A and B). The IGF1 and p38-MAPK signaling pathways were inhibited (Figure 5C), and the expression level of the EMTrelated TFs, TWIST1 and ZEB2, is inversely related to IGFBP5 level. Specifically, the mRNA level of IGFBP5 was low, whereas that of TWIST1 and ZEB2 were high. Moreover, the expression of the TBC1D3 oncogene, melanocyte-specific transcription factor/microphthalmia associated transcription factor (MITF), HIF $1 \alpha$ regulated gene CEBPD, the Rho GTPase member CDC42, growth factors CTGF and FGF2, and $\beta 4$ integrin gene ITGB4 all

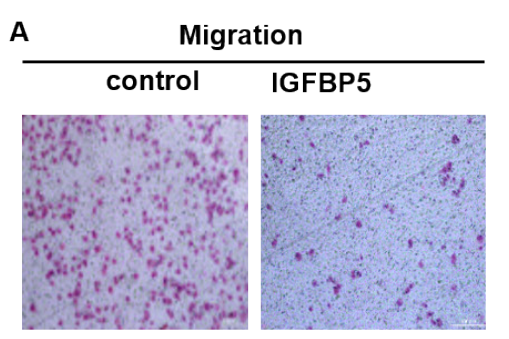

B

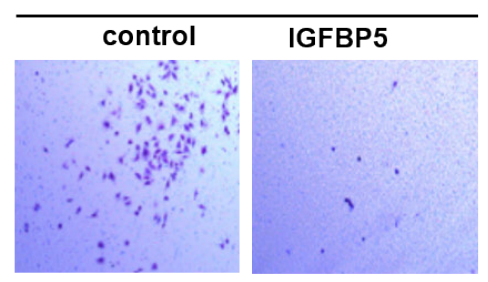

C1

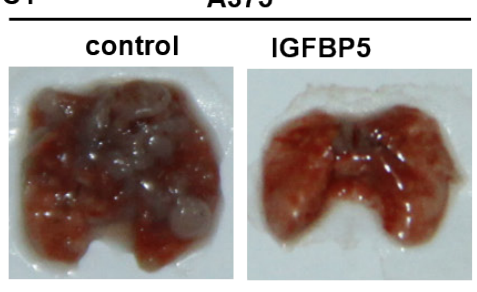

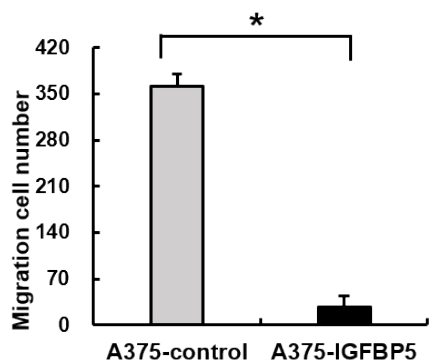
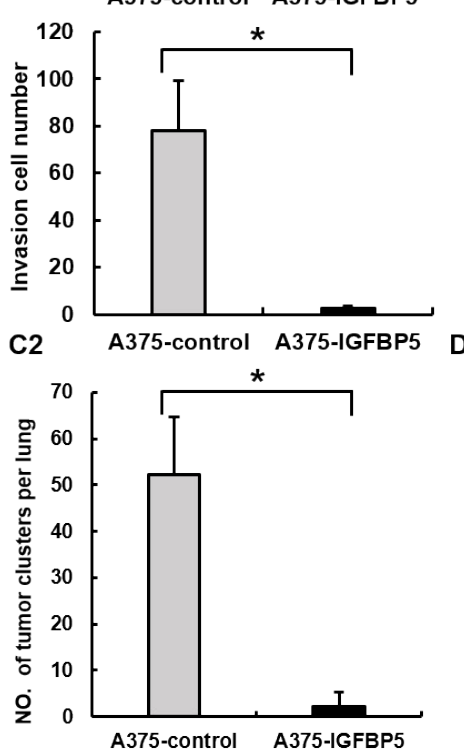

D1
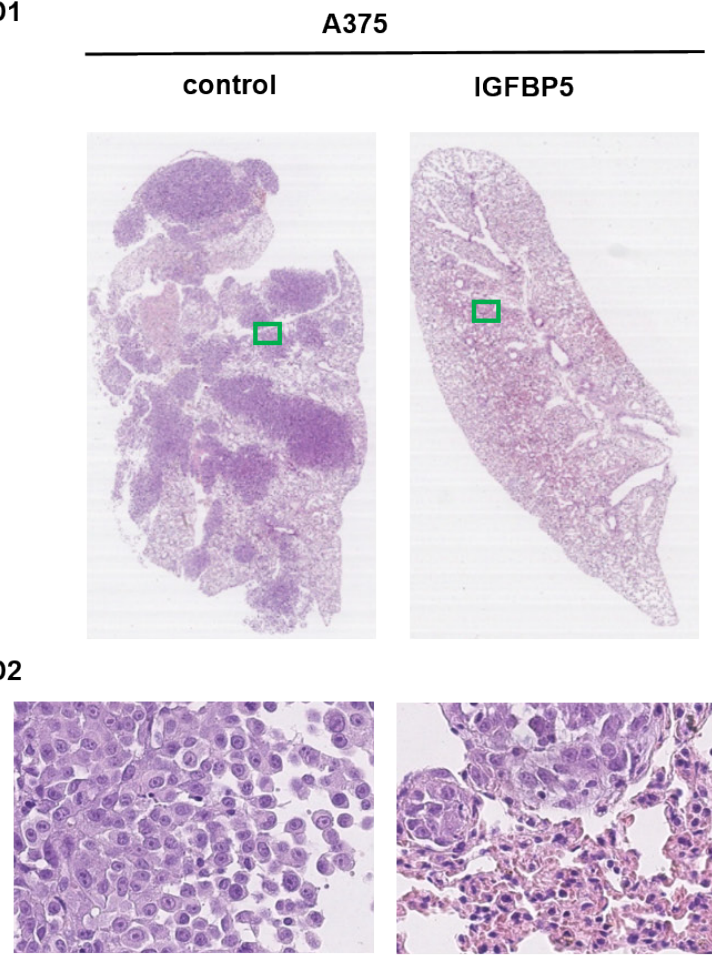

A375-control

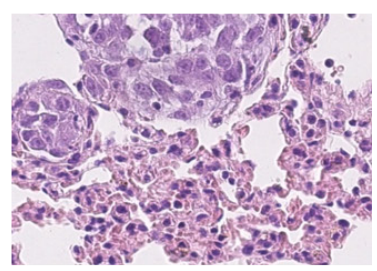

A375-IGFBP5

Figure 3: IGFBP5 inhibits cell migration and invasion in vitro and suppresses pulmonary metastasis in vivo. Transwell cell migration assay A. and Matrigel cell invasion assay B. were conducted between control cells and A375 IGFBP5 OE cells. Representative images of cells stained with H\&E (left) and the mean of migrated and invaded cells (right) were shown. Data were shown for the mean \pm SD from three independent experiments. ${ }^{*}, P<0.05$. (C1) Representative images of the lungs harvested from mice injected with vector control cells and A375 IGFBP5 OE cells were shown. (C2) The mean number of metastatic lung clusters from mice control and A375 IGFBP5 OE tumors were plotted, as analyzed by H\&E staining. *, $P<0.05$. (D1 and D2) H\&E staining of lung tumor sections and adjacent tissues from control and IGFBP5 OE mice. Representative images of the harvested lungs from injected mice were shown for each treatment. The images in D2 are the magnifications of the two green boxes in D1. 


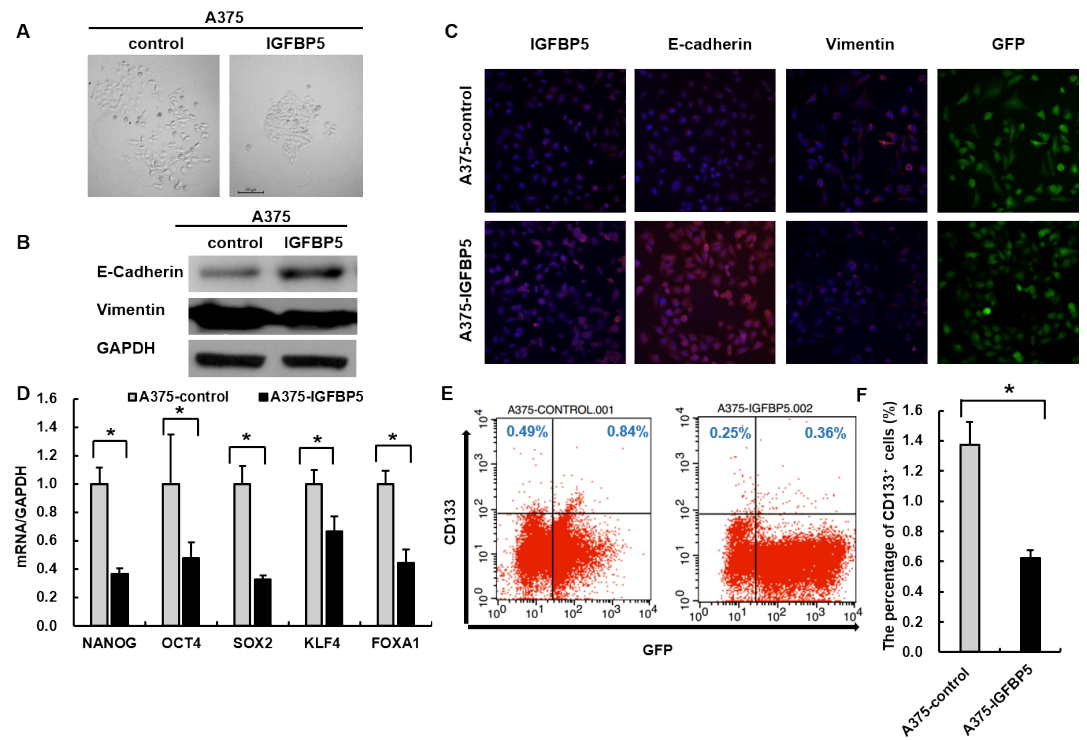

Figure 4: IGFBP5 suppresses EMT and stem cell features of tumor cells. A. Representative images illustrating the characteristic morphology of A375 control and IGFBP5 OE cell clones were shown. Magnification, $\times 200$. The expression of EMT markers was analyzed by western blots B. and immunofluorescence C. in A375 control and IGFBP5 OE cells. Nuclei were stained with DAPI. Magnification, $\times 200$. D. Assessment of relative expression levels of representative stem cell markers by qRT-PCR. Data were shown for the mean \pm SD form three independent experiments. $P$ values based on two-side Student $t$-test comparing vector control cells and A375 IGFBP5 OE tumor cells. * $P<0.05$. E. FACS analysis of stem cell marker CD133 in IGFBP5 OE cells. F. Graph demonstrates the mean \pm SD for the percent of $\mathrm{CD} 133^{+}$cells from three independent experiments. * $P<0.05$.

A

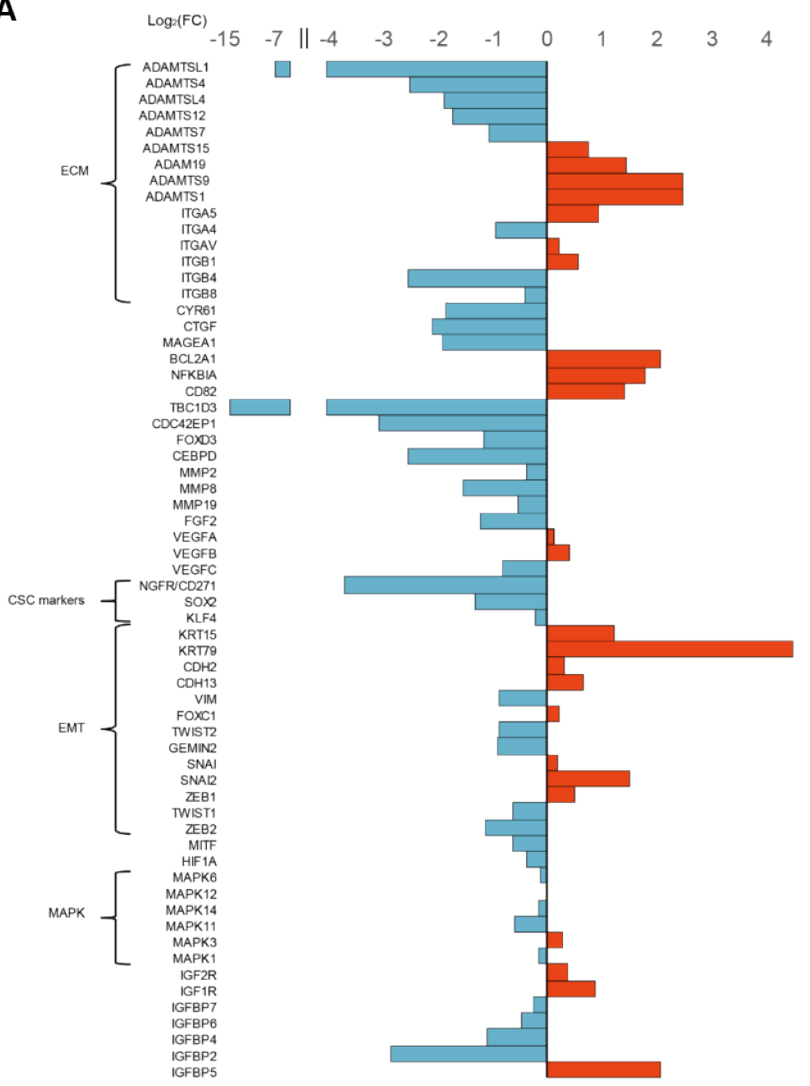

B

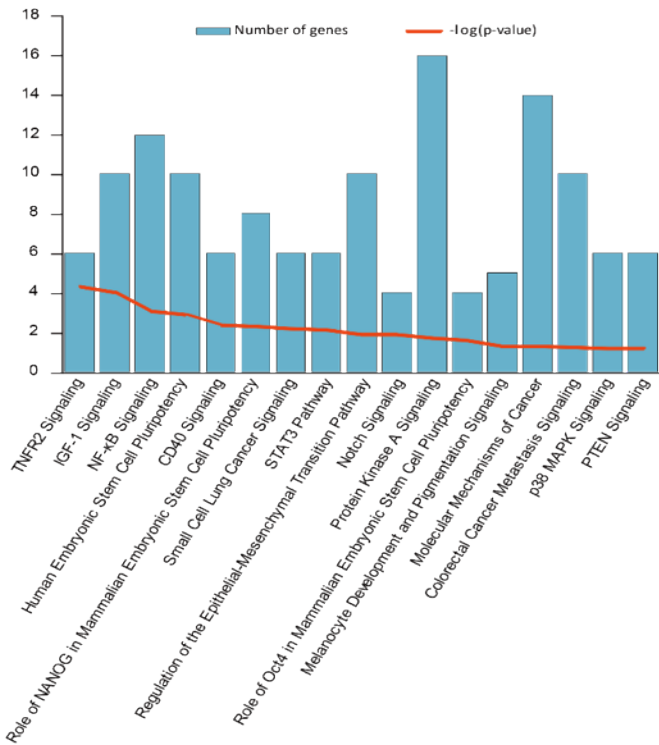

C1

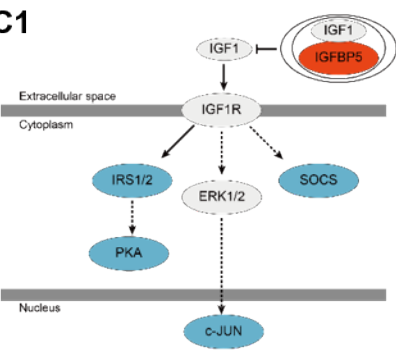

C2

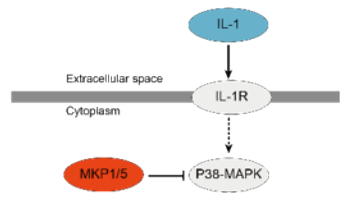

P38 MAPK signaling

Figure 5: RNA-Seq Analysis of IGFBP5 overexpression in A375 cells. A. Genes involved in tumor progression differentially expressed between IGFBP5 OE and empty vector control A375 cells. B. The most altered pathways identified with the Ingenuity Pathway Analysis (IPA) are listed, including IGF1 signaling and p38-MAPK signaling pathways. (C1 and C2) The IGF1 signaling and p38-MAPK signaling pathways were inhibited in IGFBP5 OE cells. Red color indicates up-regulation and blue color indicates down-regulation in IGFBP5 OE cells. 
decreased dramatically. These genes regulate multiple cellular activities, including cytoskeleton reorganization, Rho GTPase effector functions, cell-matrix or cell-cell adhesion, and transduction signals that regulate gene expression, cell growth, cell invasion, and metastasis (Figure 5A and Table S1).

\section{DISCUSSION}

Although IGFBP5 has been associated with various types of cancers, acting in oncogenic or tumor-suppressive roles, such as breast cancer [4, 6, 14-16], osteosarcoma $[5,17,18]$, head and neck squamous cell carcinoma [19], neuroblastoma [20], or prostate cancer [21], little is known about the role of IGFBP5 in human MM. In this study, we identify IGFBP5 as a novel inhibiting factor of tumor growth and metastasis in melanoma.

By modulating the tissue distribution of IGFs and their access to cell receptors, IGFBPs limit the bioavailability of IGFs, which are implicated in tumorigenesis [22]. The mechanism of IGFBP5 as a regulator of the oncogenic receptor ligands IGF-I and -II is well understood $[23,24]$, but there are relatively few studies demonstrating the involvement of IGFBP5 in the signaling pathways that regulate tumor growth and metastasis. Previous studies report that IGFBP5 influences pancreatic cancer cell growth and survival via the MAPK or PI3K pathway, and enhances prostate cancer growth through activation of the PI3K pathway $[25,26]$. It is widely accepted that MM is driven by the activation of MEK-ERK signaling pathway, typically through mutations in the BRAF or NRAS oncogenes, as well as upstream membrane receptors (e.g. EGFR and IGF1R) [27-32]. p38-MAPKs also play a vital role in the progression of melanoma [33, 34]. Therefore, we propose that IGFBP5 suppresses tumor growth and metastasis, including EMT, through the MEK-ERK and p38-MAPK signaling pathways. We found that the phosphorylation of ERK1/2, p38-MAPK, and IGF1R was attenuated in IGFBP5 OE cells, indicating that IGFBP5 inhibited cell proliferation and metastasis through the IGF1R-dependent pathway. Conversely, the phosphorylation of these kinases was enhanced in IGFBP5 KD cells. Furthermore, RNA-Seq pathway analysis revealed that the IGF1 and p38-MAPK signaling were inhibited in IGFBP5 OE cells.

The expression of HIF $1 \alpha$, the master regulator of tumorigenesis, tumor metastasis, and development, increased with the activation of ERK1/2-MAPK pathway
A

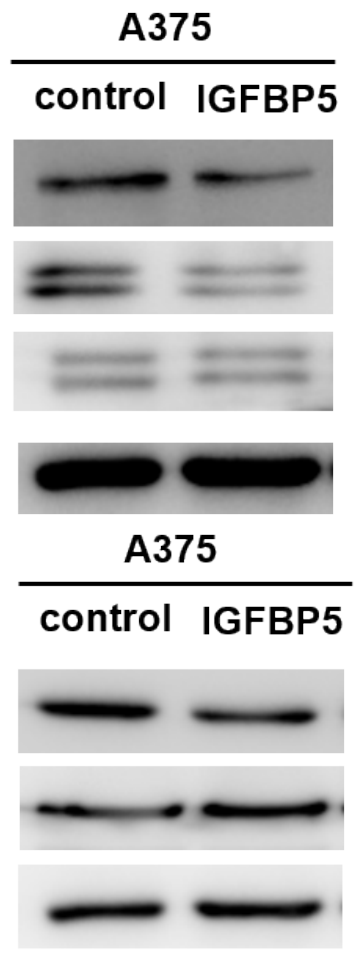

C

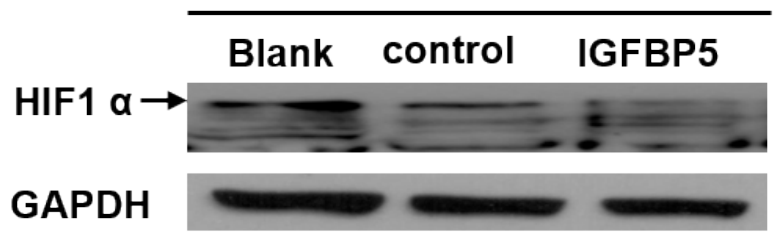

D

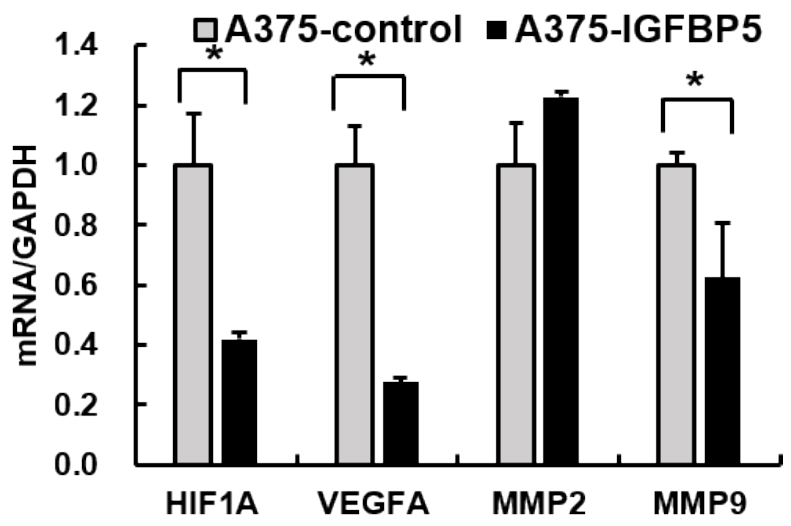

Figure 6: IGFBP5 inhibits HIF1a expression through the MAPK-ERK signaling pathway. A. and B. Western blots using specific antibodies for the phosphorylation state of IGF1R, ERK1/2, and p38-MAPK from A375 IGFBP5 OE and control cells. Phosphorylation of IGF1R, ERK1/2, and p38-MAPK was decreased in A375 cells transfected with IGFBP5. GAPDH was used as a loading control. C. Overexpression of IGFBP5 inhibited HIF1 $\alpha$ expression visualized by western blots of A375 cells. The arrow points to the band of HIF $1 \alpha$. D. Assessment of the reduced gene expression levels of VEGFA and MMP9, downstream genes regulated by HIF1 $\alpha$, in A375 IGFBP5 OE compared to control cells by qRT-PCR analysis. Data were shown for the mean $\pm \mathrm{SD}$ form three independent experiments. $P$ values based on two-side Student $t$-test comparing A375 IGFBP5 OE tumor cells and vector control cells. ${ }^{*}, P<0.05$. 
in human melanoma [35-38]. We observed that the expression of HIF1 $\alpha$ was inhibited in melanoma cells overexpressing IGFBP5, which is consistent with the inhibition of ERK1/2 and MAPK activities. Accordingly, the expression of the genes targeted by HIF $1 \alpha$, VEGF and MMPs, were downregulated in IGFBP5 OE cells. Hypoxia levels were reduced in tumor cells, resulting in decreased levels of metastasis-promoting genes (MMPs, VEGFs, FGF2, and CEBPD) thus impairing metastasis [39]. In addition, HIF $1 \alpha$ can induce the expression of IGFBPs family members, including IGFBP2 [40], IGFBP3 [41], and IGFBP6 [42], whereas HIF $1 \alpha$ expression is regulated by IGF1 signaling trigged by IGFBP1 and IGFBP2 [40-43]. In our study, we first found that up-regulation of IGFBP5 decreased HIF1 $\alpha$ expression and the other IGFBPs family members, IGFBP2, IGFBP4, IGFBP6, and IGFBP7 to some extent in melanoma cells. However, the relationship between HIF $1 \alpha$ and IGFBP5 in human melanoma cells remains to be verified.

Our data point to a negative correlation between IGFBP5 expression and EMT phenotypes. EMT is characterized by the loss of cell polarity, down-regulation of epithelial proteins most prominently ECAD, and upregulation of the mesenchymal protein, VIM, which has more recently been implicated in promoting carcinoma invasion and metastasis [44, 45]. Moreover, an increasing number of studies show that the progression of EMT can generate tumor cells with properties of CSCs [46-50]. Vijayan et al. revealed that IGFBP5 enhances epithelial cell adhesion and protects epithelial cells from TGF $\beta 1$ induced mesenchymal invasion in NMuMG cells [51]. In our study, we found that overexpression of IGFBP5 inhibits EMT and decreases the key stem cell markers NANOG, SOX2, OCT4, KLF4, whereas the knockdown of IGFBP5 leads to a repression of the epithelial phenotype, inducing a mesenchymal-like phenotype, and increasing

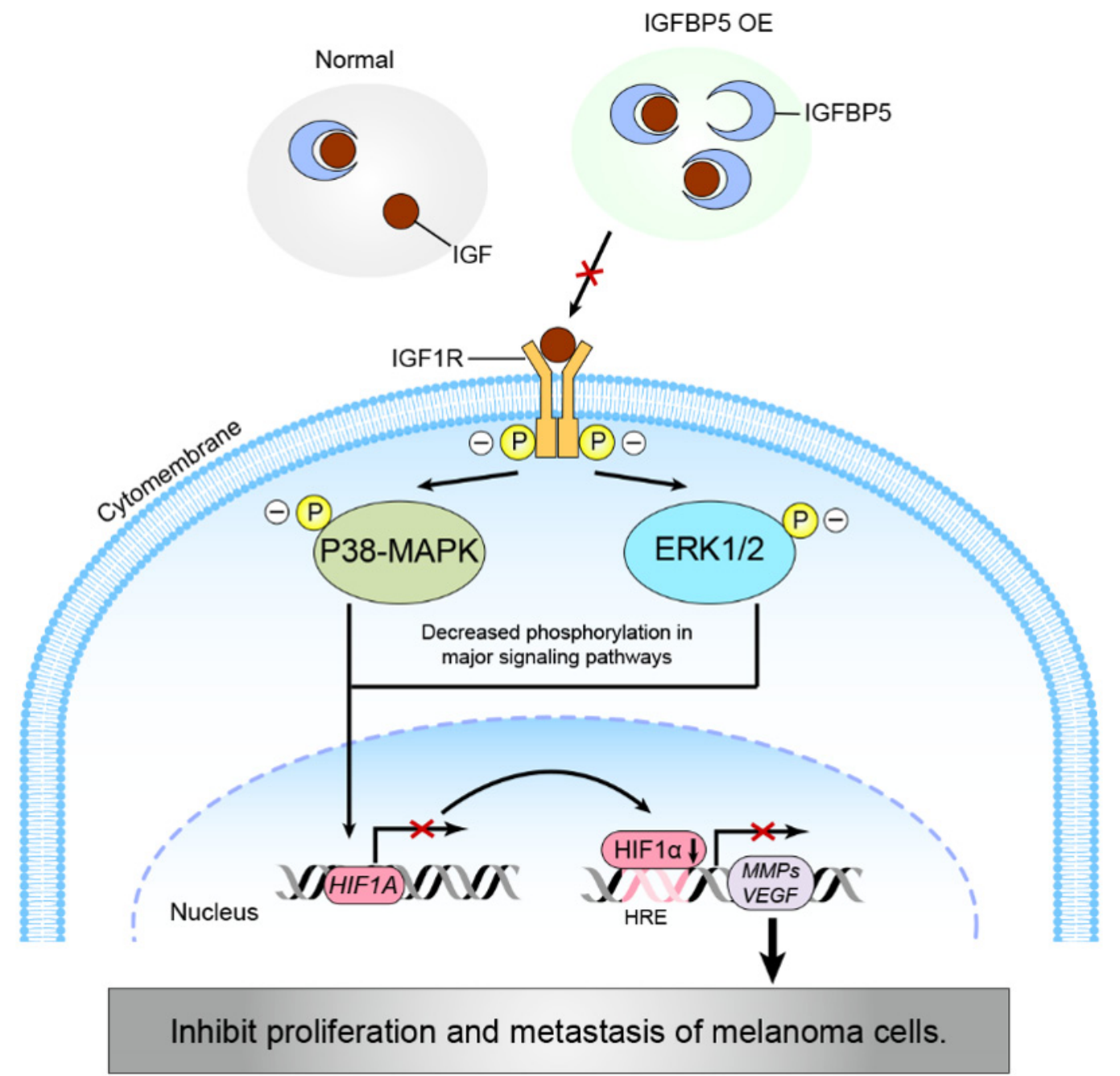

Figure 7: A schematic diagram modeling a potential pathway for the IGFBP5-IGF1R-MAPK-HIF1 $\alpha$ signaling inhibition of melanoma tumor cell growth and metastasis. IGFBP5 represses the proliferative and metastatic capabilities of cancer cells by (1) inhibiting ERK1/2 and p38-MAPK activities through an IGF1R-dependent signaling pathway and (2) down-regulating the expression of HIF $1 \alpha$ through the transcriptional inhibition of HIF1A gene expression, resulting in a decrease in VEGF and MMPs expression. 
migratory and invasive behaviors and CSC-like properties. Additionally, we purport that the IGFBP5 might suppress expression of ZEB2 and TWIST1 at the transcriptional level from the results of our RNA-Seq analysis. ZEB2 is a member of the zinc finger homeodomain enhancerbinding protein (ZEB) family, and it is both necessary and sufficient to repress ECAD transcription and trigger the EMT process in melanoma [52, 53]. For this reason, we believe that IGFBP5 suppresses EMT, at least partially, by inhibiting TWIST1 and ZEB2. We found that the CSC markers SOX2, KLF4, and CD271 (also known as NGFR) decrease dramatically in IGFBP5 OE cells in our RNASeq data, and stem cell pluripotency-related pathways were inhibited in our IPA analysis.

Analysis of our RNA-Seq data permitted an investigation of the causes and molecular mechanisms of IGFBP5 functions in IGFBP5 OE cells. Foremost, we found that many top down-regulated genes were related to cell-cell adhesion, cell-ECM adhesion, ECM proteins, and growth factors and receptors, which all promoted tumor growth and progression. Next, we found that overexpression of IGFBP5 not only resulted in a widespread oscillatory-like pattern of changes in gene expression, but also disrupted both canonical and non-canonical signaling pathways, including the IGF1 signaling, NF- $\mathrm{B}$ signaling, Notch signaling, p38MAPK signaling, EMT, stem cell pluripotency, and PTEN signaling pathways. This suggests that IGFBP5 may act as a tumor suppressor disturbing a wide array of signaling pathways. In the future, we plan to utilize proteomics techniques to further explore the changes of protein expression profiles and hope to find new factors that contribute to the inhibition of melanoma progression induced by the overexpression of IGFBP5.

In summary, we have identified IGFBP5 as a novel suppressor of the pathogenesis and metastasis of malignant melanoma by expression-manipulating experiments (Figure 7). We have demonstrated that IGFBP5 suppresses melanoma cell growth and metastasis through inhibition of the ERK1/2 and P38-MAPK pathways. Because IGFBP5 appears to exert a specific inhibitory effect on melanoma growth and metastasis, it may qualify as a useful therapeutic target against melanoma and, perhaps, other cancers.

\section{MATERIALS AND METHODS}

\section{Cell culture and tissue samples}

Normal human melanocytes, neonatal, lightly pigmented donor (HEMn-LP), and the malignant human melanoma cells, A375 and A2058, were purchased from ATCC (Manassas, VA, USA). The human melanoma cell line, UACC903, was a gift from Dr. Yongliang Zhao
(Beijing Institute of Genomics, CAS). All melanoma cell lines were maintained in Dulbecco's modified Eagle's medium (DMEM, Gibco, Grand Island, NY, USA) supplemented with $10 \%(\mathrm{v} / \mathrm{v})$ fetal bovine serum (FBS, AusGeneX, Molendinar, Qld, Australia) and penicillin (100 U/mL)-streptomycin $(0.1 \mathrm{mg} / \mathrm{mL})$ (Invitrogen, Carlsbad, CA, USA). All cells were cultured in a $37^{\circ} \mathrm{C}$, humidified, $5 \% \mathrm{CO}_{2}$ atmosphere incubator (Thermo Fisher Scientific, Waltham, MA, USA).

The acquisition of tissue samples was approved by the Chinese PLA General Hospital. We used primary melanoma samples, metastatic melanoma samples, and normal pigmented nevus samples to test the endogenous expression of IGFBP5. Informed consent was given by all patients examined. All human samples were collected in accordance with the "Declaration of Helsinki" (as revised in Edinburgh 2000).

\section{RNA isolation and quantitative real-time PCR}

Total RNA was extracted from cells and tissues using TRIzol ${ }^{\circledR}$ Reagent (Life Technologies, Carlsbad, CA, USA) according to the manufacturer's instructions, and equal mass amounts $(1 \mu \mathrm{g})$ of RNA was reverse transcribed and the cDNA was used in duplicate real-time PCRs using Maxima SYBR green/ROX qPCR master mix (Fermentas, Amherst NY, USA). Relative gene expression levels were calculated using CFX Manager Software. GAPDH was used as an internal control. The primer sequences for all qRT-PCR experiments were provided in Table S2.

\section{Cloning and plasmid construction}

Human IGFBP5 cDNA, which codes for the 272 amino acids of the IGFBP5 protein, was amplified by PCR from normal human blood with Pfu DNA Polymerase (M7741, Promega, Madison, WI, USA) and cloned into pcDNA3.1-Neo-EGFP plasmid (Invitrogen, Carlsbad, CA, USA). The cloning primers for IGFBP5 were: 5'-CCCCTCGAGATGGTGTTGCTCACCGCGGT-3' (forward) and 5'CCCGCGGCCGCTCACTCAACGTTGCTGCTGT-3' (reverse).

A375 cells were stably transduced with the IGFBP5 expression vector (pcDNA3-Neo-EGFP-IGRBP5), using Lipofectamine $^{\circledR} 2000$ according to the manufacturer's protocol. The short-hairpin RNA (shRNA) targeting IGFBP5 was cloned into a pRNATU6.1-Neo-cGFP plasmid (GenScript, Piscataway, NJ, USA)), and the resulting vector, pRNATU6.1-Neo-cGFP-shIGFBP5, was transduced into A2058 melanoma cells with Lipofectamine $^{\circledR}$ 2000. The shRNA sequences targeting IGFBP5 are provided in Table S3. Control and scramble G418-resistant clones of A375 and A2058 cells were 
generated by transfection with empty pcDNA3.1-NeoEGFP and pRNATU6.1 vectors, respectively. The transfected cells were selected for 2 weeks with G418, and individual colonies were isolated and grown. All constructs were verified by restriction enzyme digestion and standard DNA sequencing.

\section{Fluorescence activated cell sorting (FACS)}

Subconfluent cells were transfected with either pcDNA3.1-Neo-EGFP or pcDNA3.1-Neo-EGFP-IGFBP5 for A375 cells and either pRNATU6.1-Neo-cGFPscramble or pRNATU6.1-Neo-cGFP-shIGFBP5 for A2058 cells. Cells were harvested and sorted according to GFP fluorescence with a flow cytometer (BD Biosciences, Franklin Lakes, NJ, USA). Additionally, the stem cell surface marker CD133 was used for cell sorting with the anti-CD133-APC antibody (130-098-829, Miltenyi Biotec, Bergisch Gladbach, Germany).

\section{Western blots}

Western blots were performed as previously described [54]. The following antibodies were used: IGFBP5 (ab4255, Abcam, Cambridge, UK), vimentin (ab8069, Abcam), GAPDH (ab75834, Abcam), HIF1 $\alpha$ (NB100-134, Novus, St. Louis, MO, USA), IGF1RP(Try1135/1136)(3024, Cell Signaling Technology (CST), Danvers, MA, USA), ERK1/2-P (Thr202/Tyr204) (4376, CST), ERK1/2 (4695, CST), E-cadherin (3195, CST), p38-MAPK-P (Thr180/Tyr182) (9215, CST), p38-MAPK (9212, CST), sheep anti-mouse IgG (ZB-2305, ZSGBBio, Beijing, China), and sheep anti-rabbit IgG (ZB-2301, ZSGB-Bio). Enhanced chemiluminescence substrate kit (RPN2232, GE Healthcare, Piscataway, NJ, USA) was used for the chemiluminescent detection of signals with BioMax film (Kodak, Rochester, NY, USA).

\section{Immunofluorescence}

Immunofluorescence was performed as previously described [55]. Briefly, cells were incubated for $1 \mathrm{~h}$ at room temperature with the primary antibodies IGFBP5, E-cadherin, and vimentin. Next, the cells were washed three times with PBS followed by incubation with Alexa Fluor ${ }^{\circledR} 594$ goat anti-rabbit IgG (A-11037, Life Technologies) for $1 \mathrm{~h}$. After washing with PBS, the cells were examined using a Living Cell Imaging System (UltraVIEW VoX, Perkin-Elmer, Waltham, MA, USA). Cell nuclei were visualized using $2 \mu \mathrm{M} 4$, 6-diamidino2-phenylindole (DAPI) (Sigma-Aldrich, St. Louis, MO, USA).

\section{Immunohistochemistry and $\mathrm{H} \& \mathrm{E}$ staining}

Immunohistochemical staining was used to assess protein expression levels in the tissues. Formalinfixed paraffin-embedded tissue sections collected from PLA General Hospital were de-paraffinized in xylene, rehydrated through graded ethanol, and boiled for $10 \mathrm{~min}$ in citrate buffer $(10 \mathrm{mM}, \mathrm{pH} 6.0)$ for antigen retrieval. Endogenous peroxidase activity was suppressed by exposure to $3 \%$ hydrogen peroxide for $10 \mathrm{~min}$. The slides were then blocked with 5\% BSA, incubated with diluted IGFBP5 polyclonal primary antibody for $1 \mathrm{~h}$ at $37^{\circ} \mathrm{C}$, and finally incubated with goat-anti-rabbit IgG (PV-9000, ZSGB-Bio, Beijing, China) for $20 \mathrm{~min}$. The tissue was visualized with 3, 3'-diaminobenzidine (DAB) stain and counter-stained with $\mathrm{H} \& \mathrm{E}$ for microscopic examination. Immunohistochemical staining and scoring of the staining intensity was performed as previously described and blinded to any clinical data [18]. Briefly, staining score was rated as 0 (no staining), $1+$ (weak), $2+$ (moderate) or $3+$ (strong).

\section{Transwell migration and invasion assays}

A375 cells transfected with pcDNA3-Neo-EGFPIGRBP5 or empty pcDNA3-Neo-EGFP vector were plated at $1 \times 10^{5}$ per well into the upper transwell chambers and $20 \%$ FBS-containing medium was placed into the bottom chamber. After incubation at $37^{\circ} \mathrm{C}$ in $5 \% \mathrm{CO}_{2}$ for $12 \mathrm{~h}$, the cells remaining at the upper surface of the membrane were removed with a cotton swab. The cells that migrated through the $8-\mathrm{mm}$ sized pores and adhered to the lower surface of the membrane were fixed with $4 \%$ paraformaldehyde, stained with $\mathrm{H} \& \mathrm{E}$, and photographed. Transwell invasion assays were conducted as indicated for the migration assay, with the exception that the upper chamber was coated with Matrigel (dilutions range from 1:5 - 1:8, BD Biosciences) in the invasion assay.

\section{Colony formation assays and cell counting kit-8 (CCK-8) assays}

Cells were harvested seeded at 500 cells/well in 6-well plates and incubated at $37^{\circ} \mathrm{C}$ in a $5 \% \mathrm{CO}_{2}$, humidified incubator for 12 days. The medium was changed in 3-day intervals. At the end of the incubation period, the cultures were fixed with $4 \%$ paraformaldehyde and stained with crystal violet. Cell viability was measured for A375 and A2058 cells, both control and those with stable IGFBP5 expression, using the Cell Counting Kit-8 from Dojindo (CK04, Kumamoto, Japan) according to the manufacturer's instructions. After treatment with CCK-8, the absorbance was measured at $490 \mathrm{~nm}$ with a microplate reader. The absorbance values from the vector control cells 
were used as references.

\section{Xenograft models}

For tumorigenicity detection, 12 female SCID/beige mice (4-week old, Beijing Laboratory Animal Center, Beijing, China), were randomly divided into two groups (6 mice/group). Both groups received subcutaneous injections of either pcDNA3.1-Neo-EGFP vector control or A375 IGFBP5 OE cells $\left(1 \times 10^{7}\right.$ cells in $200 \mu \mathrm{L}$ PBS $)$ and shRNA vector or shIGFBP5 A2058 cells $\left(5 \times 10^{6}\right.$ cells in $200 \mu \mathrm{L}$ PBS), respectively. Tumor growth was evaluated by measuring the length and width of the tumor mass with calipers every 3 days. After approximately 30 days, the mice were sacrificed, and tumor weights were evaluated with an analytical balance. All of the animal experiments were approved by the Institutional Review Board of the Beijing Institute of Genomics, CAS, in accordance with the National Institutes of Health (NIH) Guide for the Care and Use of Laboratory Animals.

\section{Tumor metastasis assays (in vivo)}

The empty vector control or A375 IGFBP5 OE A375 cells and shRNA vector or shIGFBP5 A2058 cells were injected into the caudal veins of mice $\left(5 \times 10^{6}\right.$ cells in $200 \mu \mathrm{L} \mathrm{PBS}, 6$ mice/group). SCID mice were inspected every 3 days, killed after 6-7 weeks, and their lungs were dissected, fixed with $10 \%$ buffered formalin, and prepared for histological analysis. All experimental procedures involving animals were in accordance with the Guide for the Care and Use of Laboratory Animals (NIH publication no. 80-23, revised 1996).

\section{Transcriptome-sequencing and bioinformatics analysis}

Whole-transcriptome sequencing was conducted using Ion Proton ${ }^{\mathrm{TM}}$ sequencing system (Life Technologies). All cDNA libraries were constructed using the Ion Total RNA-Seq Kit v2 (4479789, Life Technologies) protocol; sequencing templates were prepared using the Ion One Touch ${ }^{\mathrm{TM}} 2$ system and the sequencing procedure was conducted according to the Ion PITM chip manufacturer's instructions. We used Cutadapt (v1.4.2) to ensure clean data and remove any reads shorter than 35 bp or with quality scores of less than 17. Raw reads were mapped to the reference human genome using TopHat (v2.0.13) and Bowtie 2 (v2.2.4), reaching an average mapping rate of $96 \%$. Total mapped reads were normalized using Cufflinks (v2.2.0) and SAMtools (v1.1), followed by calculation of differentially expressed reads with Cuffdiff set with the filters: $P$-value $\leq 0.05$ and fold change $\geq 2$. The resulting UniGenes were further annotated using the Gene Ontology (GO) database and Ingenuity Pathway Analysis (IPA, http://www.ingenuity. com/). The normalized RNA expression data for IGFBP5 overexpression in A375 cells were deposited in the Gene Expression Omnibus (GEO) database (accession number, GSE64693).

\section{Statistical analysis}

The two-tailed Student's t-test was used to analyze the experimental data, including qRT-PCR assay, cell proliferation, transwell assay, FACS assay and xenograft model analysis. The two sample Wilcoxon Rank-Sum test (Mann-Whitney) was used to compare the immunohistochemical scores for all pigment nevus samples and melanoma samples. Data were presented as the mean \pm standard deviation (SD). $p<0.05$ was considered statistically significant.

\section{ACKNOWLEDGMENTS}

We would like to thank Dr. Yungui Yang and Dr. Caixia Guo for their critically reading the manuscript and helpful suggestions; Liang Li and Liping Luo (Beijing Laboratory Animal Research Center) for technical support in animal assays and Dr. Junfeng Hao (Experimental Animal Pathological Laboratory, Institute of Biophysics, CAS) for her pathological technique support. This research was supported by the "Strategic Priority Research Program" of the Chinese Academy of Sciences, Stem Cell and Regenerative Medicine Research (XDA01040405), National Programs for High Technology Research and Development (863 Project, 2012AA022502) and the National Key Scientific Instrument and Equipment Development Project of China (2011YQ03013404) to X.F.; National Natural Science Foundation of China (31471236) to Y.L..

\section{CONFLICTS OF INTEREST}

The authors declare no conflict of interest

\section{REFERENCES}

1. Tripathi G, Salih DA, Drozd AC, Cosgrove RA, Cobb LJ and Pell JM. IGF-independent effects of insulin-like growth factor binding protein-5 (Igfbp5) in vivo. FASEB journal : official publication of the Federation of American Societies for Experimental Biology. 2009; 23:2616-2626.

2. Gullu G, Karabulut S and Akkiprik M. Functional roles and clinical values of insulin-like growth factor-binding protein-5 in different types of cancers. Chinese journal of cancer. 2012; 31:266-280.

3. Baxter RC. IGF binding proteins in cancer: mechanistic and clinical insights. Nature reviews Cancer. 2014; 14:329-341. 
4. Akkiprik M, Feng Y, Wang H, Chen K, Hu L, Sahin A, Krishnamurthy S, Ozer A, Hao X and Zhang W. Multifunctional roles of insulin-like growth factor binding protein 5 in breast cancer. Breast cancer research : BCR. 2008; 10:212.

5. Luther GA, Lamplot J, Chen X, Rames R, Wagner ER, Liu X, Parekh A, Huang E, Kim SH and Shen J. IGFBP5 domains exert distinct inhibitory effects on the tumorigenicity and metastasis of human osteosarcoma. Cancer letters. 2013.

6. Akkiprik M, Hu L, Sahin A, Hao X and Zhang W. The subcellular localization of IGFBP5 affects its cell growth and migration functions in breast cancer. BMC Cancer. 2009; 9:103.

7. Miller AJ and Mihm MC, Jr. Melanoma. The New England journal of medicine. 2006; 355(1):51-65.

8. Siegel R, Ma J, Zou Z and Jemal A. Cancer statistics, 2014. CA Cancer J Clin. 2014; 64:9-29.

9. Xi Y, Nakajima G, Hamil T, Fodstad O, Riker A and Ju J. Association of insulin-like growth factor binding protein-3 expression with melanoma progression. Molecular cancer therapeutics. 2006; 5:3078-3084.

10. Oy GF, Slipicevic A, Davidson B, Solberg Faye R, Maelandsmo GM and Florenes VA. Biological effects induced by insulin-like growth factor binding protein 3 (IGFBP-3) in malignant melanoma. International journal of cancer Journal international du cancer. 2010; 126:350-361.

11. Contois LW, Akalu A, Caron JM, Tweedie E, Cretu A, Henderson T, Liaw L, Friesel R, Vary C and Brooks PC. Inhibition of tumor-associated alphavbeta3 integrin regulates the angiogenic switch by enhancing expression of IGFBP-4 leading to reduced melanoma growth and angiogenesis in vivo. Angiogenesis. 2014.

12. Naspi A, Panasiti V, Abbate F, Roberti V, Devirgiliis V, Curzio M, Borghi M, Lozupone F, Carotti S, Morini S, Gaudio E, Calvieri S and Londei P. Insulin-like-growthfactor-binding-protein-3 (IGFBP-3) contrasts melanoma progression in vitro and in vivo. PLoS One. 2014; 9:e98641.

13. Zhao H, Li Y, Wang S, Yang Y, Wang J, Ruan X, Yang Y, Cai K, Zhang B, Cui P, Yan J, Zhao Y, Wakeland EK, Li Q, $\mathrm{Hu}$ S and Fang X. Whole transcriptome RNA-seq analysis: tumorigenesis and metastasis of melanoma. Gene. 2014; 548:234-243.

14. Butt AJ, Dickson KA, McDougall F and Baxter RC. Insulinlike growth factor-binding protein-5 inhibits the growth of human breast cancer cells in vitro and in vivo. Journal of Biological Chemistry. 2003; 278:29676-29685.

15. Sureshbabu A, Okajima H, Yamanaka D, Tonner E, Shastri S, Maycock J, Szymanowska M, Shand J, Takahashi S, Beattie J, Allan G and Flint D. IGFBP5 induces cell adhesion, increases cell survival and inhibits cell migration in MCF-7 human breast cancer cells. J Cell Sci. 2012; 125:1693-1705.

16. Liu BY, Soloviev I, Huang X, Chang P, Ernst JA, Polakis $p$ and Sakanaka C. Mammary tumor regression elicited by Wnt signaling inhibitor requires IGFBP5. Cancer Res. 2012; 72:1568-1578.

17. Mukherjee A and Rotwein P. Insulin-like growth factor binding protein-5 in osteogenesis: facilitator or inhibitor? Growth hormone \& IGF research : official journal of the Growth Hormone Research Society and the International IGF Research Society. 2007; 17:179-185.

18. Su Y, Wagner ER, Luo Q, Huang J, Chen L, He BC, Zuo GW, Shi Q, Zhang BQ, Zhu G, Bi Y, Luo J, Luo X, Kim SH, Shen J, Rastegar F, et al. Insulin-like growth factor binding protein 5 suppresses tumor growth and metastasis of human osteosarcoma. Oncogene. 2011; 30:3907-3917.

19. Hung PS, Kao SY, Shih YH, Chiou SH, Liu CJ, Chang KW and Lin SC. Insulin-like growth factor binding protein-5 (IGFBP-5) suppresses the tumourigenesis of head and neck squamous cell carcinoma. The Journal of pathology. 2008; 214:368-376.

20. Cesi V, Vitali R, Tanno B, Giuffrida ML, Sesti F, Mancini $\mathrm{C}$ and Raschella G. Insulin-like growth factor binding protein 5: contribution to growth and differentiation of neuroblastoma cells. Annals of the New York Academy of Sciences. 2004; 1028:59-68.

21. Xu C, Graf LF, Fazli L, Coleman IM, Mauldin DE, Li D, Nelson PS, Gleave M, Plymate SR, Cox ME, Torok-Storb BJ and Knudsen BS. Regulation of global gene expression in the bone marrow microenvironment by androgen: androgen ablation increases insulin-like growth factor binding protein-5 expression. The Prostate. 2007; 67:16211629.

22. Pollak M. The insulin and insulin-like growth factor receptor family in neoplasia: an update. Nature reviews Cancer. 2012; 12:159-169.

23. Imai Y, Moralez A, Andag U, Clarke JB, Busby WH, Jr. and Clemmons DR. Substitutions for hydrophobic amino acids in the N-terminal domains of IGFBP-3 and -5 markedly reduce IGF-I binding and alter their biologic actions. The Journal of biological chemistry. 2000; 275(24):1818818194.

24. Zeslawski W, Beisel HG, Kamionka M, Kalus W, Engh RA, Huber R, Lang K and Holak TA. The interaction of insulin-like growth factor-I with the N-terminal domain of IGFBP-5. The EMBO journal. 2001; 20:3638-3644.

25. Johnson SK and Haun RS. Insulin-like growth factor binding protein-5 influences pancreatic cancer cell growth. World journal of gastroenterology : WJG. 2009; 15:33553366.

26. Maeda H, Yonou H, Yano K, Ishii G, Saito S and Ochiai A. Prostate-specific antigen enhances bioavailability of insulinlike growth factor by degrading insulin-like growth factor binding protein 5. Biochem Biophys Res Commun. 2009; 381:311-316.

27. Goodall J, Wellbrock C, Dexter TJ, Roberts K, Marais $\mathrm{R}$ and Goding CR. The Brn-2 transcription factor links 
activated BRAF to melanoma proliferation. Molecular and cellular biology. 2004; 24:2923-2931.

28. McCubrey JA, Steelman LS, Abrams SL, Lee JT, Chang F, Bertrand FE, Navolanic PM, Terrian DM, Franklin RA, D'Assoro AB, Salisbury JL, Mazzarino MC, Stivala F and Libra M. Roles of the RAF/MEK/ERK and PI3K/ PTEN/AKT pathways in malignant transformation and drug resistance. Advances in Enzyme Regulation. 2006; 46:249279.

29. McCubrey JA, Steelman LS, Chappell WH, Abrams SL, Wong EW, Chang F, Lehmann B, Terrian DM, Milella M, Tafuri A, Stivala F, Libra M, Basecke J, Evangelisti C, Martelli AM and Franklin RA. Roles of the Raf/MEK/ERK pathway in cell growth, malignant transformation and drug resistance. Biochimica et biophysica acta. 2007; 1773:12631284.

30. Karasic TB, Hei TK and Ivanov VN. Disruption of IGF1R signaling increases TRAIL-induced apoptosis: a new potential therapy for the treatment of melanoma. Experimental cell research. 2010; 316:1994-2007.

31. Yajima I, Kumasaka MY, Thang ND, Goto Y, Takeda K, Yamanoshita O, Iida M, Ohgami N, Tamura H, Kawamoto $\mathrm{Y}$ and Kato M. RAS/RAF/MEK/ERK and PI3K/PTEN/ AKT Signaling in Malignant Melanoma Progression and Therapy. Dermatology research and practice. 2012; 2012:354191.

32. Wang AX and Qi XY. Targeting RAS/RAF/MEK/ERK signaling in metastatic melanoma. IUBMB life. 2013; 65:748-758.

33. Denkert C, Siegert A, Leclere A, Turzynski A and Hauptmann S. An inhibitor of stress-activated MAP-kinases reduces invasion and MMP-2 expression of malignant melanoma cells. Clinical \& experimental metastasis. 2002; 19:79-85.

34. del Barco Barrantes I and Nebreda AR. Roles of p38 MAPKs in invasion and metastasis. Biochemical Society transactions. 2012; 40:79-84.

35. Mills C, Joshi S and Niles R. Expression and function of hypoxia inducible factor-1 alpha in human melanoma under non-hypoxic conditions. Molecular cancer. 2009; 8:104.

36. Vaupel P. Hypoxia and aggressive tumor phenotype: implications for therapy and prognosis. The oncologist. 2008; 13 Suppl 3:21-26.

37. Hanna SC, Krishnan B, Bailey ST, Moschos SJ, Kuan PF, Shimamura T, Osborne LD, Siegel MB, Duncan LM, O'Brien ET, 3rd, Superfine R, Miller CR, Simon MC, Wong KK and Kim WY. HIF1alpha and HIF2alpha independently activate SRC to promote melanoma metastases. The Journal of clinical investigation. 2013; 123:2078-2093.

38. Giatromanolaki A, Sivridis E, Kouskoukis C, Gatter KC, Harris AL and Koukourakis MI. Hypoxia-inducible factors $1 \alpha$ and $2 \alpha$ are related to vascular endothelial growth factor expression and a poorer prognosis in nodular malignant melanomas of the skin. Melanoma research. 2003; 13:493-
501.

39. Mazzone M, Dettori D, Leite de Oliveira R, Loges S, Schmidt T, Jonckx B, Tian YM, Lanahan AA, Pollard P, Ruiz de Almodovar C, De Smet F, Vinckier S, Aragones J, Debackere K, Luttun A, Wyns S, et al. Heterozygous deficiency of PHD2 restores tumor oxygenation and inhibits metastasis via endothelial normalization. Cell. 2009; 136:839-851.

40. Feldser D, Agani F, Iyer NV, Pak B, Ferreira G and Semenza GL. Reciprocal positive regulation of hypoxiainducible factor $1 \alpha$ and insulin-like growth factor 2. Cancer research. 1999; 59:3915-3918.

41. Natsuizaka M, Naganuma S, Kagawa S, Ohashi S, Ahmadi A, Subramanian H, Chang S, Nakagawa KJ, Ji X and Liebhaber SA. Hypoxia induces IGFBP3 in esophageal squamous cancer cells through HIF- $1 \alpha$-mediated mRNA transcription and continuous protein synthesis. The FASEB Journal. 2012; 26:2620-2630.

42. Zhang $\mathrm{C}$, Lu L, Li Y, Wang X, Zhou J, Liu Y, Fu P, Gallicchio MA, Bach LA and Duan C. IGF binding protein-6 expression in vascular endothelial cells is induced by hypoxia and plays a negative role in tumor angiogenesis. International Journal of Cancer. 2012; 130:2003-2012.

43. Treins C, Giorgetti-Peraldi S, Murdaca J, MonthouëlKartmann M-N and Van Obberghen E. Regulation of hypoxia-inducible factor (HIF)-1 activity and expression of HIF hydroxylases in response to insulin-like growth factor I. Molecular Endocrinology. 2005; 19:1304-1317.

44. Yang $\mathrm{J}$ and Weinberg RA. Epithelial-Mesenchymal Transition: At the Crossroads of Development and Tumor Metastasis. Developmental Cell. 2008; 14:818-829.

45. Tsai JH and Yang J. Epithelial-mesenchymal plasticity in carcinoma metastasis. Genes \& development. 2013; 27:2192-2206

46. Mani SA, Guo W, Liao MJ, Eaton EN, Ayyanan A, Zhou AY, Brooks M, Reinhard F, Zhang CC, Shipitsin M, Campbell LL, Polyak K, Brisken C, Yang J and Weinberg RA. The epithelial-mesenchymal transition generates cells with properties of stem cells. Cell. 2008; 133:704-715.

47. Polyak K and Weinberg RA. Transitions between epithelial and mesenchymal states: acquisition of malignant and stem cell traits. Nature reviews Cancer. 2009; 9:265-273.

48. Hollier BG, Evans K and Mani SA. The epithelial-tomesenchymal transition and cancer stem cells: a coalition against cancer therapies. Journal of mammary gland biology and neoplasia. 2009; 14:29-43.

49. Brabletz T. EMT and MET in metastasis: where are the cancer stem cells? Cancer cell. 2012; 22:699-701.

50. Zimmerer R, Korn P, Demougin P, Kampmann A, Kokemuller H, Eckardt A, Gellrich N-C and Tavassol F. Functional features of cancer stem cells in melanoma cell lines. Cancer cell international. 2013; 13:78.

51. Vijayan A, Guha D, Ameer F, Kaziri I, Mooney CC, Bennett L, Sureshbabu A, Tonner E, Beattie J, Allan GJ, 
Edwards $\mathrm{J}$ and Flint DJ. IGFBP-5 enhances epithelial cell adhesion and protects epithelial cells from TGF $\beta 1$ induced mesenchymal invasion. The International Journal of Biochemistry \& Cell Biology. 2013; 45:2774-2785.

52. Caramel J, Papadogeorgakis E, Hill L, Browne Gareth J, Richard G, Wierinckx A, Saldanha G, Osborne J, Hutchinson P, Tse G, Lachuer J, Puisieux A, Pringle JH, Ansieau S and Tulchinsky E. A Switch in the Expression of Embryonic EMT-Inducers Drives the Development of Malignant Melanoma. Cancer cell. 2013; 24:466-480.

53. Denecker G, Vandamme N, Akay O, Koludrovic D, Taminau J, Lemeire K, Gheldof A, De Craene B, Van Gele M, Brochez L, Udupi GM, Rafferty M, Balint B, Gallagher WM, Ghanem G, Huylebroeck D, et al. Identification of a ZEB2-MITF-ZEB1 transcriptional network that controls melanogenesis and melanoma progression. Cell death and differentiation. 2014; 21:1250-1261.

54. Leung KP, Qu YH, Qiao DF, Xie WB, Li DR, Xu JT, Wang HJ and Yue X. Critical role of insulin-like growth factor binding protein-5 in methamphetamine-induced apoptosis in cardiomyocytes. Molecular medicine reports. 2014; 10:2306-2312.

55. Mehta HH, Gao Q, Galet C, Paharkova V, Wan J, Said J, Sohn JJ, Lawson G, Cohen P, Cobb LJ and Lee K-W. IGFBP-3 Is a Metastasis Suppression Gene in Prostate Cancer. Cancer Research. 2011; 71:5154-5163. 